Questionnaires, a subjective tool, were used in 13 studies. It should be noted that 8 different questionnaires were used in these studies with recurrent use of the IPAQ (international validated questionnaire in general population) and SQUASH (validated in English language in RA). In these studies, patients were predominantly sedentary with a proportion of patients meeting WHO physical activity recommendations ranging from 20 to $77 \%$. It appears that Scandinavian patients are clearly the most active.

Concerning objective measurement tools, 9 studies evaluated the level of physical activity using activity tracker. 7 studies used the accelerometer, 1 used the VO2 max, 1 used an actimeter. All studies showed a sedentary behavior. In these studies, the results were expressed as energy expenditure and not as a percentage of patients meeting WHO recommendations. Thus, the comparison between the two methods is difficult, but accelerometer showed a significant decrease in the level of physical activity in RA.

The oldest studies (2002 and 2007) showed that only 30\% of patient met the WHO recommendations, but the recent studies (2017 and 2018) showed the same prevalence of sedentary behavior. The disease activity and the disease duration were comparable between the different studies. Conclusion: Patients with rheumatoid arthritis present a sedentary behavior. Objective and subjective tools showed the low level of physical activity over the past decade. These data illustrate the necessity of the promotion of physical activity in rheumatoid arthritis.

Disclosure of Interests: None declared

DOI: 10.1136/annrheumdis-2019-eular.7385

\section{FRI0171 CLINICAL RESPONSES IN PATIENTS WITH INADEQUATE RESPONSE TO BDMARDS UPON TREATMENT WITH UPADACITINIB}

Michael Weinblatt ${ }^{1}$, Glen Thomson ${ }^{2},{\text { Kun } \mathrm{Chen}^{3} \text {, Sebastian Meerwein }}^{4}$ Casey Schlacher ${ }^{3}$, John Cush ${ }^{5} .{ }^{1}$ Brigham and Women's Hospital, Boston, United States of America; ${ }^{2}$ CIADS Research, Winnipeg, Canada; ${ }^{3}$ AbbVie, North Chicago, United States of America; ${ }^{4}$ AbbVie Germany GmbH and Co. KG, Ludwigshafen am Rhein, Germany; ${ }^{5}$ Baylor University Medical Center Station, Dallas, United States of America

Background: Upadacitinib (UPA), a JAK1-selective inhibitor, demonstrated efficacy in the SELECT-BEYOND study in patients (pts) with moderate to severe rheumatoid arthritis (RA) on a stable dose of csDMARDs who had inadequate response (IR) or intolerance to bDMARDs,

Objectives: In this analysis we evaluated clinical responses among pts receiving UPA and placebo (PBO) based on the number and mechanism of action (MOA) of prior bDMARDs.

Methods: 498 pts were randomized to UPA $15 \mathrm{mg}$ or UPA $30 \mathrm{mg}$ once daily (QD) or PBO for 12 weeks (wks), after which pts on $\mathrm{PBO}$ received UPA 15 or $30 \mathrm{mg}$ QD from Wk 12 onwards. ${ }^{1}$ Pts were subgrouped by the number and/or MOA of $\operatorname{bDMARD}(s)$ received prior to enrollment: 1) lack of efficacy (LoE) to $\geq 1$ anti-TNF, 2) LoE to an anti-IL-6, and 3) the number of prior bDMARDs ( 1 vs 2 vs $\geq 3$ ). ACR20/50/70 responses, DAS28-CRP low disease activity (LDA, $\leq 3.2)$, CDAI LDA $(\leq 10)$, and CDAI remission $(\leq 2.8)$ were evaluated at $W k$ 12. The frequency and percentage of treatment-emergent adverse events (TEAE) in each subgroup was assessed over the first 12 wks. Missing values of the efficacy endpoints were imputed using non-responder imputation (NRI). Nominal $P$-values are reported without multiplicity adjustment

Results: Overall baseline disease duration was 13 years. The majority of pts had LoE to $\geq 1$ anti-TNF $(449,90 \%)$; 88 (18\%) had LoE to an antiIL-6; 235 (47\%), 137(28\%), and $125(25 \%)$ had been treated with 1, 2, or $\geq 3$ prior bDMARDs, respectively. ${ }^{1}$ At $W k 12$, clinical responses were numerically, and often statistically, better for pts receiving either dose of UPA vs PBO, irrespective of their prior bDMARD exposure and the number of prior bDMARDs received. As most pts had LoE to $\geq 1$ anti-TNF, responses in this group were comparable to the overall study population (Table 1). Pts with LoE to an anti-IL-6 receiving UPA 15 or $30 \mathrm{mg} Q D$ experienced improvements vs PBO, particularly in achieving LDA and remission, although responses in these pts were generally lower compared to the overall study population. As expected, there was a trend towards lower responses as the number of prior bDMARDs increased (Table 2). Responses at Wk 24 were generally consistent with those at Wk 12 (data not shown). TEAEs across the subgroups were consistent with the overall study population (data not shown).

Conclusion: At Wk 12, treatment with UPA at either 15 or $30 \mathrm{mg}$ QD led to significantly better clinical responses vs PBO in this treatmentrefractory population, including in pts with LoE to an anti-TNF or an anti-
$\mathrm{IL}-6$, and those who had IR/intolerance to 1,2 or $\geq 3$ prior bDMARDs, with consistent safety profiles as to the overall study population.

Acknowledgement: AbbVie, Inc was the study sponsor, contributed to study design, data collection, analysis \& interpretation, and to writing, reviewing, and approval of final version. Medical writing support was provided by Naina Barretto, PhD, of AbbVie, Inc.
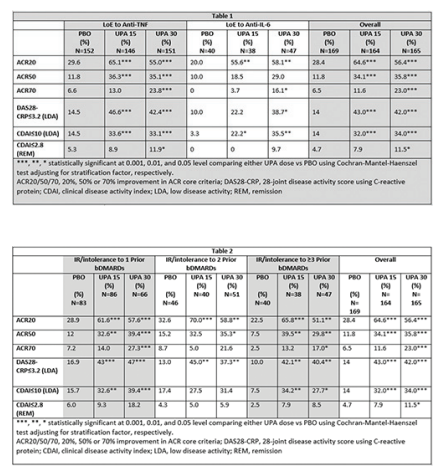

Disclosure of Interests: Michael Weinblatt Shareholder of: Lycera, Scipher, Vorso, Inmedix, Grant/research support from: Amgen, BMS, Crescendo Bioscience, Sanofi/Regeneron, Consultant for: AbbVie, Amgen, Crescendo Bioscience, Gilead, GSK, Lycera, Merck, Novartis, Pfizer, Roche, Samsung, SetPoint, BMS, Corrona, Eli Lilly and Company, Glen Thomson Grant/research support from: AbbVie, Consultant for: Amgen, Kun Chen Shareholder of: Abbvie, Employee of: Abbvie, Sebastian Meerwein Share holder of: AbbVie, Employee of: AbbVie Deutschland $\mathrm{GmbH}$ \& Co. KG, Casey Schlacher Shareholder of: AbbVie, Employee of: AbbVie, John Cush Consultant for: AbbVie, Celgene, Novartis, AstraZeneca and Genentech; AbbVie, UCB, Novartis, BMS, Amgen, Genentech, Celgene, Lilly, and Horizon

DOI: 10.1136/annrheumdis-2019-eular.3083

\section{FRI0172 A PROSPECTIVE AUDIT OF A PATIENT COHORT PRESCRIBED HYDROXYCHLOROQUINE FOR RHEUMATOID ARTHRITIS AND OTHER INFLAMMATORY RHEUMATIC DISEASES IN ORDER TO PRIORITISE RETINOPATHY SCREENING AND ESTIMATE THE NEED FOR DRUG EDUCATION APPOINTMENTS}

Brandon Yeo ${ }^{1}$, Audrey Low ${ }^{2}$, Alexandra Chadwick ${ }^{2}$, Sarah Wills ${ }^{2} .{ }^{1}$ University of Manchester, Faculty of Biology, Medicine, and Health, Manchester, United Kingdom; ${ }^{2}$ Salford Royal NHS Foundation Trust, Rheumatology, Salford, United Kingdom

Background: Hydroxychloroquine (HCQ) is prescribed for rheumatoid arthritis (RA), systemic lupus erythematosus (SLE) and inflammatory osteoarthritis (IOA). A potential side effect of $\mathrm{HCQ}$ is drug-induced retinopathy, with an increased risk reported for patients taking $>5 \mathrm{mg} / \mathrm{kg} /$ day and those who have renal impairment.

In the United Kingdom, the Royal College of Ophthalmologists (RCO) has published new screening guidelines for $\mathrm{HCQ}$, recommending 1) patients receive doses $<5 \mathrm{mg} / \mathrm{kg} /$ day and 2) all patients planning to be on $\mathrm{HCQ}$ long term ( $\geq 5$ years) should receive baseline eye examination ideally within 6 months of starting $\mathrm{HCQ}$ and definitely within 1 year.

Objectives: This audit aimed to: 1) audit dose prescription by body weight, 2) estimate the screening burden on ophthalmology services, 3) estimate service needs for additional drug education appointments to counsel patients starting HCQ.

Methods: A list of all patients who were started on HCQ from January 2017 to February 2018 was obtained from the outpatient pharmacy at Salford Royal Hospital. Demographic and clinical data were extracted from electronic patient records. High-risk patients were defined as those who were prescribed an initial dose of $>5 \mathrm{mg} / \mathrm{kg} /$ day or those with an eGFR $\leq 50 \mathrm{ml} / \mathrm{min} / 1.73 \mathrm{~m}^{2}$. Patients were followed until the most recent follow-up visit by July 2018 to determine drug persistence and reasons for $\mathrm{HCQ}$ cessation, if any.

Results: 177 patients were started on HCQ, with most (62\%) diagnosed with rheumatoid arthritis (Table). Most patients were female $(76 \%)$ and a third $(35 \%)$ were older than 60 years old. 9 patients $(5.1 \%)$ had impaired renal function. 83 patients (47\%) were prescribed an initial daily dose of $\mathrm{HCQ}>5 \mathrm{mg} / \mathrm{kg} / \mathrm{day}$. By July 2018 (follow-up duration 6-19 months), 127 patients $(71.8 \%)$ remained on $\mathrm{HCQ}$ and will need baseline eye screening 